\title{
SEARCHING THE MEDICAL LITERATURE
}

\author{
By R. S. Smith, B.A., F.L.A.
}

Librarian, St. Mary's Hospital Medical School, Paddington, W.2.

The librarian in his professional training is frequently told that the goal of good librarianship is reader service. In the sphere of medical librarianship this implies a readiness to search the literature at the request of the enquirer, and the sheer volume of medical literature coupled with the pressure on the medical man's time have led to the task being delegated more and more to the library staff. No librarian would wish to curtail his usefulness, but it is'a matter for regret that so few doctors have developed the technique of making their own searches. No literature is so well served with bibliographical aids as is that of medicine. A short time spent on familiarizing oneself with the main indexes and reference works will prove a most profitable investment.

It is the purpose of this article to discuss briefly the main works which would be utilised in a search of the recent literature. The works listed are those which one might hope to see in the average medical collection, and are all in English. For a wider search than that which the writer has in mind the resources of a large collection would need to be consulted, and trained help would be essential. For these reasons no mention is made of those monuments of medical bibliography, the Index-Catalogue of the Library of the SurgeonGeneral's Office and the old Index Medicus, both of which are indispensable for a search of the older literature.

The queries which lead to a search of the literature will be seen to fall into two categories: (a) 'Specific' queries, in which a particular book or article is sought of which the author or other details are known; $(b)$ 'Subject' queries, in which information is sought on a particular topic or area of knowledge. Most of the works listed will be useful for both purposes, but some, as will be shown, are more useful for one purpose than for the other.

We begin with the one work with which no doctor fails to make an acquaintance-the Quarterly Cumulative Index .Medicus (Q.C.I.M.), I, 1927-. As has often been pointed out, the Q.C.I.M. is no longer quarterly nor cumulative, but is intended to appear every six months. It indexes the medical literature which has appeared during the half year shown on the cover. Its scope is world-wide, though it can only deal, of course, with part of the world output. Articles are indexed by author's name and by subject in one alphabetical sequence. There are references from joint authors, extra subject entries where necessary, and a system of cross-references between allied subjects which make this index easy to use. At the beginning of each volume there is a list of journals indexed with the abbreviated titles used and place of publication, and also a list of books which have appeared in the six months arranged both by author and subject.

The convenience of use of the Q.C.I.M. is such that if it lived up to its title and published in prompt quarterly cumulations, searching the current literature would present few problems But at the time of writing (October 1952) the last volume of the Q.C.I.M. to appear is that for the second half of $195^{\circ}$, whilst the volume covering July-December 1949 has yet to appear. The situation would be most difficult were it not for our next index, the Current List of Medical Literature (C.L.M.L.), which in its present form begins with volume 19, 1950, and is issued by the Armed Forces Medical Library, Washington, D.C. Speed of publication is the objective here, and the index does not have the easy-to-use form of the Q.C.I.M. But its use is indispensable and its make-up is soon learnt. Each monthly issue consists of two sections: a register section in which the journals indexed in that particular issue appear in alphabetical order, with their contents listed and numbered; and following this an author and subject index referring by number to the first part. A cumulated index for the $195 \mathrm{I}$ volume (with subjects and authors in separate sequences) was issued as the December $195 \mathrm{I}$ issue, but it is proposed in future to publish a cumulated index every six months. These cumulations also contain an up-to-date list of the periodicals indexed, but without details of publisher or place of publication.

When using the C.L.M.L. it must be remembered that the periodicals are indexed as they 
arrive at the Armed Forces Medical Library, and an issue of the C.L.M.L. for a particular month will index periodicals which were published up to six months before and sometimes even earlier. Thus, unlike the Q.C.I.M., the C.L.M.L. for I95I does not index the literature for the whole of $195 \mathrm{I}$, but roughly for the period September $195^{\circ}$ to September 195I, with wide variations for different journals. Efforts are still being made to improve the C.L.M.L., and a recent innovation has been the asterisking in the index of articles in foreign languages. Despite the improvements, use of the C.L.M.L is time-consuming, but it is obligatory today for up-to-date surveys. It should be pointed out that the C.L.M.L. indexes certain titles not included in the Q.C.I.M., and vice versa, so that both will need to be used for fuller searches in the world literature.

Both the Q.C.I.M. and the C.L.M.L. are comprehensive indexes, equally useful for author and subject enquiry. The abstracting journal can be used similarly for author and subject approach to the significant material which has appeared in the specialties covered by these journals. But there are certain drawbacks, to be mentioned later, which in fact limit their usefulness. The most frequent use of abstracting journals will be by those wishing to be kept informed on the important work appearing in their field. The main abstracting journals in current use are the following: Abstracts of World Medicine, 1, 1947(this incorporates some of the material previously published in the Abstracts of World Surgery); Biological Abstracts, 1, 1926- (in nine sections and, as the title implies, covering mainly the preclinical fields); British Abstracts, Section A III, formerly British Chemical and Physiological $A b$ stracts, 1926- (again strongest in the pre-clinical subjects); Bulletin of Hygrene, 1, 1926-; Excerpta Medica, I, 1947- (in 15 sections covering all the branches of medicine); Nutritional Abstracts and Reviews, 1, 1931-; Psychological Abstracts, 1, 1927-; Tropical Diseases Bulletin, 1, 1912-; Tuberculosis Index, 1, 1946-. Mention should also be made of those journals which include a section of abstracts, of which the most important is the International Abstract of Surgery included in Surgery, Gynecology and Obstetrics.

Most abstracting journals have author and sometimes subject indexes to the individual parts and publish annual cumulated indexes (Biological ' Abstracts issues no index with its monthly parts, which considerably detracts from its value). Unfortunately all abstract journals have certain endemic diseases - the abstracts appear late; they are, of course, selective, and the cumulated indexes to completed volumes are often very late (the latest volume indexes to appear for the
Abstracts of World Medicine, for example, are $\stackrel{0}{0}$ those for 1950). These factors limit their useful- ‡ ness, as already pointed out, but abstracts remain $z$ our second line of attack in searches of the $\stackrel{\mathbb{Q}}{\stackrel{Q}{Q}}$ literature.

Before proceeding to a consideration of the works useful mainly for embarking on a subject $\stackrel{\oplus}{\stackrel{F}{+}}$ search, mention should be made of aids to the location of details about books. The printed Catalogue of Lezois' Medical, Scientific and Tech- $\frac{}{T}$ nical Lending Library lists books included in the $\stackrel{\mathbb{Q}}{\circledR}$ library up to the end of 1948 and, together with its bi-monthly supplements issued to date, is $\vec{P}$ invaluable. This catalogue includes a subject index, but it does not give publishers' names, $\vec{\omega}$ and we must remember that it is a selective list $\stackrel{\circ}{\circ}$ giving one library's holdings. If an approximate date is known, the book's details can be looked 3 . for in the lists given at the beginning of each volume of the Q.C.I.M. More comprehensive is $\omega$ the annual U.S. Armed Forces Medical Library Author Catalog, first published for 1949. If these sources fail, recourse should be had to the general $\omega$ bibliographies of books in print and of new books 은 issued which are to be found in most large lib- raries. Of these the most used is $\mathrm{H}$. W. Wilson's $\subseteq$ Cumulative Book Index, which includes British as well as American books. For British books $\overrightarrow{0}$ there is the British National Bibliography, 195\%, 잉 which lists only books published in Britain, whilst. for British books published before 195 Whitaker's Cumulative Book List would be used. The card catalogues of the library in which the search was being carried out would naturally be $\frac{\emptyset}{\not}$ consulted as well.

The remaining works to be mentioned are all $\overrightarrow{\hat{O}}$ used mainly to answer subject queries. This 3 group includes the annual reviews (Annual Review? of Physiology, 1, 1939-; Annual Review of Bio-? chemistry, 1, 1932-; Annual Review of Medicine, 흠 I, 1950-), the yearbook series (Yearbook of Medicine, Yearbook of General Surgery, etc.) and the annual progress volumes issued by the British. Encyclopaedia of Medical Practice and British $\bigcirc$ Surgical Practice. These annual reviews of progress will often be useful, but they are selective, 음 and the fact that the topic sought does not appear $>$ may mean simply that it has not been chosen for을. inclusion in that particular review, not that there has been nothing of importance to report.

Then there are the more recent editions of the $N^{N}$ Recent Advances series (e.g. Sir W. S. Duke- N Elder's Recent Advances in Ophthalmology, 4tho edition, 195I), the Advances series (e.g. Advanceso in Pediatrics, 1, 1942-) and the Modern Trends series (e.g. F. Avery Jones' Modern Trends in? Gastro-enterology, 195I). These attempt with varying degrees of success to present an up-to-date 
picture of a specialty or a particular study and are thus closely allied to the comprehensive and authoritative textbooks and monographs.

Finally we have the 'review' periodicals (Physiological Reviews, I, 1921-; Medicine, I, 1922-; Pharmacological Reviews, I, I949-; , etc.) which provide invaluable summaries not only of recent work on a subject, but also of the significant earlier work. Mention here should also be made of those periodicals, such as the American fournal of the Medical Sciences and the Annals of Internal Medicine, which provide surveys of progress in selected fields of medicine (these surveys are most usefully listed each year in the Annual Review of Medicine).

Let us now consider the steps whereby a search for recent material on a particular subject can be undertaken. The subject is first searched in the C.L.M.L. and then in the Q.C.I.M., and it is probable that these indexes will reveal the information we are seeking or else an authoritative article which will be a lead into the literature of the topic. Our searches of these indices is almost certain to bring us material on our topic (such is the blessed prolixity of medical literature), but the authoritative article or the good bibliography may have eluded us. The other sources are then tackled in order - the appropriate abstracting journals are scanned, then the annual reviews and yearbooks, the latest and best textbooks and monographs and the Recent Advances type of book and, finally, the review journals mentioned above. From all these approaches will emerge the bibliography of recent material on our topic which is sought. The bibliography will, of course, be as comprehensive as time will allow, or in proportion to the importance of the subject, and may vary from several hundred entries on a fairly broad topic to a handful of entries on a rare condition.

If we should now wish to bring the survey right up to date considerable difficulty would be experienced. The larger library may maintain its own index to current material, but this is beyond the powers of the small institution, and a laborious search would need to be undertaken through the title-pages of recent issues of as many journals as possible. In practice such a search would probably be confined to a small selection of the leading periodicals. And here I would like to end with a suggestion which I am sure would go a long way to meeting this real difficulty of making a truly up-to-date search. Both the Q.C.I.M. and the C.L.M.L. attempt a world-wide coverage of the medical literature, and the need for making available as wide an indexing as possible of the world literature is obvious. New techniques and vital new approaches may be reported in quite obscure journals. Nevertheless. I feel sure that an up-to-date indexing of around 200 of the leading English-language journals would provide the answer to a very large proportion of the questions needing a search in the material which has appeared since the latest listing in the C.L.M.L. Such an index, possibly issued fortnightly or better still weekly, would surely not be beyond the resources of British medical librarianship. It would be invaluable to the small institutions and could provide a ' core ' for the more elaborate indexes maintained by individual research organizations. The issues of such an index would not normally be retained after the monthly issues of the C.L.M.L. had caught up with them, but individual doctors might well wish to subscribe to the index and file it for their personal use. If the index could be issued in the format of the C.L.M.L. it would also serve the purpose of a bulletin, giving a conspectus week by week of the contents of the most important medical journals.

The writer is well aware that the production costs of even such a modest index as that suggested might prove prohibitive, but surely more than one librarian must have felt that he would sacrifice one of the abstracting services in favour of a truly up-to-date, even if restricted, current index, for the use of his readers.

\section{RUTHIN CASTLE, NORTH WALES}

A Clinic for the diagnosis and treatment of Internal Diseases (except Mental or Infectious Diseases). The Clinic is provided with a staff of doctors, technicians and nurses.

The surroundings are beautiful. The climate is mild. There is central heating throughout. The annual rainfall is 30.5 inches, that is, less than the average for England.

The Fees are inclusive and vary according to the room occupied.

For particulars apply to THE SECRETARY, Ruthin Castle, North Wales.

Telegrams: Castle, Ruthin.

Telephone: Ruthin 66 